1. MBBS, FCPS (Psychiatry) Assistant Professor Psychiatry Gujranwala Medical College.

2. MBBS, FCPS (Psychiatry) Assistant Professor Psychiatry Services Institute of Medical Sciences, Lahore.

3. MBBS, FCPS (Psychiatry)

Associate Professor Psychiatry Services Institute of Medical Sciences, Lahore.

4. MBBS, FCPS (Psychiatry) Associate Professor Psychiatry M. Islam Medical and Dental College, Gujranwala.

5. MBBS, FCPS

Assistant Professor Psychiatry Sughra Shafee Medical College, Narowal.

6. MS (Clinical Psychology)

Correspondence Address: Dr. Aysha Butt

Department of Psychiatry

Services Institute of Medical Sciences, Lahore.

doctoraisha@yahoo.com

Article received on:

26/03/2020

Accepted for publication:

27/06/2020

\section{Relationship between work flow and burnout in medical professionals.}

Saqib Bajwa ${ }^{1}$, Aysha Butt ${ }^{2}$, Nauman Mazhar ${ }^{3}$, Shahid Warris ${ }^{4}$, Muhammad Tariq $^{5}$, Rabbia Ashraf $^{6}$

ABSTRACT... Medical profession due to its vast diversity and sensitivity can exert great stress and exhaustion among working professionals. Objectives: The present research was aimed to explore the relationship between Work Flow and Burnout in medical professionals. Study Design: Correlational Research Design was used with convenient sampling strategy. Setting: Rashid Latif Medical Collage. Period: July to October 2019. Material \& Methods: Work related Flow $^{13}$ and Copenhagen Burnout Inventory ${ }^{15}$ were used to measure the variables. Correlation and Regression were used. Result: Significant inverse relationship between work flow and burnout. Similarly, Work enjoyment subscale of Work Flow come out to be the significant predictor of burnout and its subscale. Conclusion: research indicates that professionals who enjoy their work and keep their self-engaged in while working does not get easily exhausted.

Key words: $\quad$ Burnout, Engagement, Flow, Medical Professionals, Work.

Article Citation: Bajwa S, Butt A, Mazhar N, Warris S, Tariq M, Ashraf R. Relationship between work flow and burnout in medical professionals. Professional Med J 2020; 27(11):2517-2522. https://doi.org/10.29309/TPMJ/2020.27.11.4650

\section{INTRODUCTION}

Medical professionals require a great deal of commitment, empathy and professional responsibility. It is observed that people in this field not only put efforts to solve the problems of their client but also get involved emotionally with their work and thus they may internalize the problems of their client which may induce stress in them. As it is very demanding profession so they found no time to relax and detach themselves from the problems. Professionals who get overwhelmed by these problems which may induce burnout in them, effecting their performance and their interpersonal relationship. However, on other hand it has been seen that professionals who in this regard get intrinsic motivation from their work this may play a role to deal with burnout.

Flow is the mental condition of operation in which a person is completely retention in the task assigned, complete abortion and enjoyment in the process of performing a task. ${ }^{1}$ In flow, demand of a circumstance matches the individual's capacities, and the individual is occupied completely in the demonstration of doing the task. In flow, the individual loses consciousness and a feeling of the progression of time and enters an alternate level of understanding. ${ }^{2}$

With reference to previous literature ${ }^{3}$ theoretically apply the idea of flow in work circumstance, and characterized flow as a fleeting involvement with work. He described work flow in three subcategories of absorption, work enjoyment and characteristic intrinsic work motivation. Absorption in an undertaking shows the nonappearance of the self, and a converging of your mindfulness into the action you are occupied with. Work Enjoyment state that employees who get pleasure and satisfaction from their work and feel internal satisfaction, such employees make a very affirmative judgment regarding work life quality. ${ }^{4}$ Acceding to ${ }^{5}$ this happiness and pleasure is the result of cognitive and emotional assessments of the flow understanding. At last, Intrinsic Work Motivation (IWM) it state the urge to carry out an work related activity with the purpose of feeling intrinsic happiness and satisfaction. ${ }^{6}$

An important factor of flow is the equilibrium 
between the sense of difficulty and ability ${ }^{7}$ i.e. at the point when a challenge is greater than one's level of abilities and one wind up noticeably on edge and stress. Then again, when the level of expertise surpasses the span of challenge, one ends up plainly exhausted, bored and diverted, flow is the experience of just amidst these states. The balance between these two states is key focus. Flow assumes a critical part in the workplace as flow is related with accomplishment, its advancement could have solid ramifications in expanding workplace fulfillment and achievement.

Burnout is defined as elevated level of prolonged stress related to job, that create tension and strain in person. Individual often deal inappropriately with stress in a defensive manner, such that they detach their self psychologically from work and become rigid, indifferent and pessimist. ${ }^{8}$ Physicians, have to deal with intense emotionally charged people frequently. They have to deal with emotions like fear, despair, anxiety, guilt or anger ${ }^{9}$ dealing with such strain emotion exhaust them emotionally and physically. Burnout is basically due to deprivation of person emotional recourses which are essential to deal with such emotional charged individuals. ${ }^{10}$

Symptoms of work stress and burnout can manifest in many forums like physical, behavioral and emotional. Physical can be in the forum of migraine, Gl problem, loss of appetite, cold, body aces, weight loss and sleep problem. Emotional problem can manifest in forum of, feeling of helplessness, anxiety, depression, guilt or exhaustion. On the other hand behavioral symptoms may show up as boredom, detention, lack in performance or efficacy or chatting idly during work hour which may lead to low morale at work also. ${ }^{11}$

Not only this but if the experience of burnout continues, it may lead to development of negative attitude toward work, client or even in their general life. Individual may find it difficult to interact with other or maintain a balanced relationship between their work and private life. This can affect their clients, friends and family members. Many people indulge in substance abuse, isolation, watching
TV or kill time on internet, some try to cope poorly by trying to keep them busy with destructive social active. Some physicians expect to meet their own needs met by patient who came to seek assistance. $^{12}$

As a healing profession, doctors meet with varied overwhelming patients and each day they get in touch with heart-wrenching stories and the immensely difficult life situations of the patients who come to seek help and relief. When interacting with patient they have to be compassionate and empathetic toward them. In such case if the doctors lack motivations or social skills to engage with patients then they themselves become exhausted or bored which may in turn affect their work competency. Mental health is associated with higher productivity, better performance, more consistent work attendance, and fewer work place accidents. As when a doctor is free of depression, anxiety, excessive stress and other psychological problems, they are more able to live their lives to the fullest.

Present study will contribute in the growing research of relationship between work flow and burnout in medical professionals. This study will provide an insight for administrative authorities about the preventive measures of burnout and promotion of intrinsic motivation and better working conditions for the employees to bring forth frequent positive effects, on their work productivity and work satisfaction.

The objective of the research is to investigate the relationship between Work Flow and Burnout in medical professionals.

\section{HYPOTHESIS}

Work Flow has negative relationship with Burnout Burnout will be negatively predicted by Work Flow.

\section{MATERIAL \& METHODS}

Co relational research design was used and inferential statistics was done to test the hypothesis. Licensed practicing healthcare professionals with at least one year of experience were included in study. 
The sample consist of 168 including Male $(n=55)$ and Female $(n=113)$. Medical Professionals from both Public $(n=78)$ and private sector $(n=79)$ were taken. $85 \%$ of participants had age ranges from $31-40$ and $41 \%$ of participants were working 7-9 hour per day. Majority respondent (72.5\%) were married and majority of respondents (92.3\%) state that the profession was of their own choice.

\section{MEASURING INSTRUMENTS}

\section{Personal Information Sheet}

It was developed by the researcher that consists of information regarding participant's age, religion, birth-order, education, marital status, nature of job and working hours.

\section{Work Related Flow}

Flow at work was assessed with Work- related flow scale. ${ }^{13}$ The scale consists of 13 items, with 4 items measuring absorption defined as nonappearance of the self, 4 items assessing work enjoyment i.e. in which employees get pleasure and satisfaction from their work and 5 items measuring intrinsic motivation state that urge to carry out an work related activity with the purpose of feeling intrinsic happiness and satisfaction. Respondents indicated how often they experienced elements of flow during the preceding week on a seven point scale $(1=$ never, $7=$ everyday $)$. Bakker $(2008)^{13}$ reported satisfactory Cronbach's alpha for all the subscales (Work Enjoyment $=.90$; Absorption $=$ .80 ; Intrinsic Work Motivation $=.75)$. In present research the overall reliability of the tool was good i.e. 0.87 (Work Enjoyment $=.84$; Absorption = .78 ; Intrinsic Work Motivation $=.86$ ).

\section{Copenhagen Burnout Inventory}

Copenhagen Burnout Inventory (CBI) was used to assess the feelings of emotional, physical and psychological exhaustion. It was developed by Kristensen et al. ${ }^{14}$ and had 19 item with three subdimensions, 6 items measured personal burnout i.e. the degree of physical and psychological exhaustion and fatigue experienced by a person, 7 item measured work-related burnout as the level of physical and psychological fatigue perceived by the person as related to his/her work and 6 item to assess client-related burnout is the extent of physical and psychological exhaustion perceived by the person as related to his/her work with clients. The scale had higher correlations among and them and an internal consistency above .85. In present research significantly high reliability was found i.e. .94. (Personal Burnout $=.93$; Work Burnout $=.85$; Client Related Burnout $=.92$ ). The scale were scored on Linker type scale of always (100), often (75) sometimes (50), seldom (25) and never (0). The average scores on each sub-scale indicate the degree of burnout.

\section{PROCEDURE}

The study was started after approval from the ethical committee of hospital. Medical health professionals were approached from indoor and outdoor unit of different department of hospital fulfilling inclusion and exclusion criteria. Each participant was provided with detailed information regarding the research and consent was taken to make sure that they are willing to participate in the research. The participants were assured about confidentiality of their responses and anonymity of their identity. It was also be clarified that they are free to ask any question related to research and that they had the right to quit the research at any time but their participation to complete the research was encouraged. All the research questionnaires were self-administered online by the participants.

\section{RESULTS}

Inferential statistics include Pearson product moment correlation to explore the relationship in work flow and burnout in medical professionals.

Table-I showed that there significant inverse relationship between work flow and burnout which indicates that high the person has flow experiences, lower the level of burnout they would experience. Among the subscale of Work Flow, work enjoyment and intrinsic work motivation was found to be significant negative relationship with Burnout total and its subscale work and client related burnout. This shows that medical professionals who have greater work achievement, fulfilled work environment and work enjoyment experience less burnout during work and while dealing with their client. This signifies 
that doctors who experience flow are relatively enthusiastically occupied in their surroundings to gain positive reward and motivation from work and in turn suffer less from burnout.

Hypothesis 2 state that there would likely to be predictive relationship between Work Flow and Burnout among medical professionals. It was also hypothesized that work flow is likely to negatively predict Burnout. Hierarchical regression was used in order to assess the predictive role of work flow.

Table-Il showed that Work enjoyment subscale of Work Flow come out to be the significant predictor of burnout and its subscale. Burnout sub component Work related burnout $(F(3,164)$ $=8.79, \mathrm{p}<.001)$ explained $13 \%$ of variance and client related burnout $(F(13,118)=3.98, p<.001)$ is predicted by variance of $17 \%$. It referred that $12 \%$ of the total variance in burnout total was explained by Work Flow $(F(3,164)=7.78, p<.001)$.
This shows that the engaged professionals which tale their work as a source of enjoyment and satisfaction experience less burnout as compare to others.

\section{DISCUSSION}

Medical personals cater individuals from various backgrounds and oversee people intense circumstances. Their work requires them to communicate effectively with their patients and at the same time with their friends and families. Since it a healing profession a doctors had burdens of responsibility for patient's complete care and betterment. In addition, working disreputably long and taxing hours combined with pressure to appear tough and invulnerable in front of their patients and colleagues leads to enormous levels of stress that many doctors seem unable to escape. This can contrarily affect their work and personal life.

\begin{tabular}{|c|c|c|c|c|c|c|c|c|c|c|}
\hline Measures & 1 & 2 & 3 & 4 & 5 & 6 & 7 & 8 & $\mathbf{M}$ & SD \\
\hline 2. Work enjoyment & & - & $.72^{\star \star}$ & $.84^{* *}$ & -.11 & $-.36^{\star \star}$ & $-.40^{\star \star}$ & $-.34^{\star *}$ & 19.5 & 5.5 \\
\hline 3. Intrinsic work motivation & & & - & $.89 * \star$ & .07 & $-.21 * \star$ & $-.33^{\star \star}$ & $-.17^{\star}$ & 19.3 & 8.1 \\
\hline 4. Total flow & & & & - & -.02 & $-.28 * \star$ & $-.33^{\star \star}$ & $-.24^{\star *}$ & 55.5 & 14.9 \\
\hline 6. Work burnout & & & & & & - & $.65^{\star \star}$ & $.92^{\star \star}$ & 12.6 & 6.6 \\
\hline 7. Client burnout & & & & & & & - & $.80 * *$ & 10.0 & 5.7 \\
\hline 8. Total burnout & & & & & & & & - & 34.9 & 16.1 \\
\hline
\end{tabular}

Table-I. Correlational analysis between subscales of works flow and burnout in medical professionals. * Correlation is significant at .05 level (two tailed)

** Correlation is significant at .01 level (two taile)

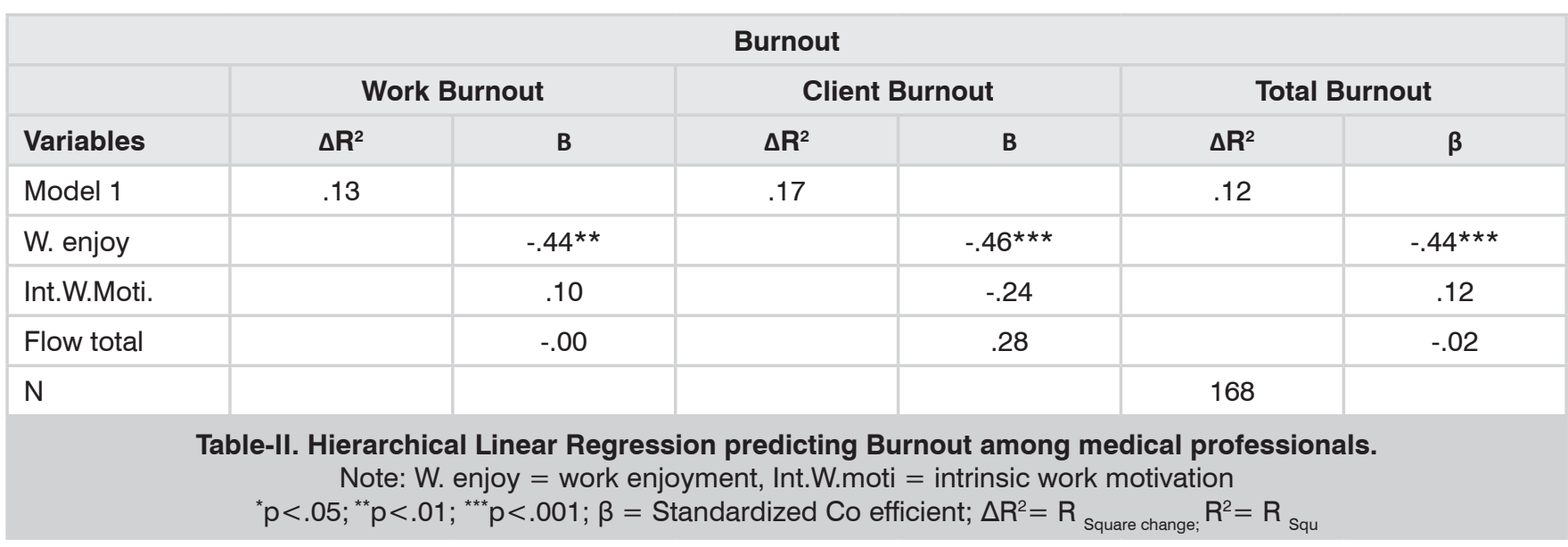


Keeping in mind the psychological and physical benefits of low Burnout we inferred to find out the positive predictor of burnout among medical professionals. The present study was conducted to assess Work Flow and burnout in medical professionals. The aim of the study was to explore the positive predictor against Burnout. The study included $N=168$ participant, both male $(n=55)$ and female $(n=113)$ of average age $30-40$ years. Medical professionals were taken from both Govt. $(n=78)$ and Private sector $(n=79)$.

The result supported first hypothesis and highly significant relationship was found between variables. A significant negative relationship was found between work enjoyment, intrinsic work motivation and flow total with burnout total and its subscales work and client related Burnout. Medical professionals require intense cognitive focus and dedication which some doctors may find difficult to cope up. This leads toward detachment from work which trigger burnout as the energy get depleted when one is detract from his path. However, an engaged doctors contains a sense of energetic and effective connection with their work environment and better able to deal well with work demands by using their energies in a constructive way.

The findings of the present study are well supported by the previous literature, thus the result are in lined with previous study. Qualitative findings of Schaufeli et al.'s ${ }^{15}$ also evident that engaged individuals are committed and satisfied with their jobs. Demerouti et al., ${ }^{16}$ reported similar result and found positive correlations between work commitment and all three components of work engagement.

Similarly, work enjoyment the subscale of work flow come out to be negatively predictor of burnout and its subscales. Work Enjoyment state that employees who get pleasure and satisfaction from their work and feel internal satisfaction, such employees make a very affirmative judgment regarding work life quality. ${ }^{17}$ This showed that professionals that enjoy their work and keep their self-engaged in happiness while working do not get easily exhausted. They find their work amusing and find pleasure in their job. Research ${ }^{18}$ also showed that despite those individuals who experience burnout, employees who are engaged have a feeling of lively and energetic, effectively well connected with the work they do and they consider themselves to better able to deal with job stress and its tough demands. This showed that doctors work hard because they had a strong and irresistible inner drive because for them work is fun.

Medical professionals are the fundamental unit of Mental Health Profession, qualitative study can be conducted to find the detailed account of problems arises in professionals due to lack of emotional engagement. It is important to focus on factors (e.g. inability to manage stress) which may affect their performance as professionals so that these factors can be managed. Arranging training session and workshops to teach Medical professionals self-care behaviors and strategies will help to make them better Professionals.

\section{CONCLUSION}

From the results explained above it is concluded that there is a significant relationship between Work flow and Burnout. Moreover it was concluded that professionals who feel happiness in working and enjoy their work experience less burnout and have low perceived pressure felt due to their job.

Copyright $(27$ June, 2020.

\section{REFERENCES}

1. Fen CM, Isa I, Chu CW, Ling C, Ling SY. Development and validation of a mental wellbeing scale in Singapore. Psychology. 2013 Jun 24;4(07):592.

2. Linley PA, Joseph S. Positive change following trauma and adversity: A Review. J Trauma Stress. 2004 Feb;17(1):11-21

3. Bakker AB. Flow among music teachers and their students: The crossover of peak experiences. Journal of Vocational Behavior. 2005; 66(1): 26-44.

4. Veenhoven R. Conditions of happiness. Netherlands: Springer; 1984. 
5. Diener E. Subjective well-being. The science of happiness and a proposal for a national index. The American Psychologist. 2000; 55(1): 34-43.

6. Deci EL, Ryan RM. Intrinsic motivation and selfdetermination in human behavior. New York: Plenum; 1985.

7. Nakamura J, Csikszentmihalyi M. Flow theory and research. In S.J. Lopez, C.R. Snyder (Eds.), Oxford handbook of positive psychology 2nd ed. Oxford: Oxford University Press; 2009:195- 206.

8. Cherniss $C$. Social and emotional competence in the workplace. In R. Bar-On \& J. D. A. Parker (Eds.), The handbook of emotional intelligence: Theory, development, assessment, and application at home, school, and in the workplace. San Francisco: JosseyBass; 2000: 433-458.

9. Maslach C, Jackson SE. Leiter MP. MBI: The maslach burnout inventory: Manual. Palo Alto, CA: Consulting Psychologists Press; 1996.

10. Farmer $\mathrm{S}$. The relationship of emotional intelligence to burnout and job satisfaction among nurses in early nursing practice (dissertation). Salt Lake City: The University of Utah; 2004 December.

11. Schaufeli W, Taris T, Rhenen W. Workaholism, Burnout, and Work Engagement: Three of a Kind or Three Different Kinds of Employee Well-Being? Applied Psychology An International Review. 2008; 57(2),173203.
12. Salvagioni D, Melanda FN, Mesas AE, González AD., Gabani FL, Andrade SM. Physical, psychological and occupational consequences of job burnout: $A$ systematic review of prospective studies. PloS one. 2017 Oct 4; 12(10).

13. Bakker AB, Schaufeli WB. Positive organizational behavior: Engaged employees in flourishing organizations. JOB. 2008; 29(2): 147-154.

14. Kristensen TS, Borritz M, Villadsen E, Christensen KB. The copenhagen burnout inventory: A new tool for the assessment of burnout. Work \& Stress. 2005; 19 (3):192-207.

15. Schaufeli WB, Bakker AB, Hoogduin K, Schaap C, Kladler A. On the clinical validity of the maslach burnout inventory and the burnout measure. Psychology \& Health.2001; 16: 565-582.

16. Demerouti E, Bakker A, Nachreiner F, Schaufeli, W. The job demands-resources model of burnout. The Journal of applied psychology. 2001; 86(3): 499-512. doi.10.1037/0021-9010.86.3.499.

17. Nawijn J, Veenhoven R. Happiness through Leisure. Positive leisure science: From subjective experience to social contexts. Netherlands: Springer Science Business Media; 2012 Apr:193-209.

18. Burke RJ, Matthiesen SB. Correlates of flow at work among Norwegian Journalists. Journal of Transnational Management. 2005; 10(2):49-58.

\begin{tabular}{|c|c|c|c|}
\hline \multicolumn{4}{|c|}{ AUTHORSHIP AND CONTRIBUTION DECLARATION } \\
\hline Sr. \# & Author(s) Full Name & Contribution to the paper & Author(s) Signature \\
\hline 1 & & $\begin{array}{l}\text { As per ICMJE recommendation, } \\
\text { author fulfilled all four criteria. }\end{array}$ & \\
\hline 2 & Aysha Butt & $\begin{array}{l}\text { Fulfilled ICMJE recommendation } \\
\text { criteria. }\end{array}$ & $X(k x)$ \\
\hline 3 & Nauman Mazhar & $\begin{array}{l}\text { Fulfilled ICMJE criteria for } \\
\text { authorship. }\end{array}$ & 氶 \\
\hline 4 & Shahid Warris & $\begin{array}{l}\text { Fulfilled ICMJE criteria for } \\
\text { authorship. }\end{array}$ & Shalded. \\
\hline 5 & Muhammad Tariq & $\begin{array}{l}\text { Fulfilled ICMJE criteria for } \\
\text { authorship. }\end{array}$ & Afrie \\
\hline 6 & Rabbia Ashraf & $\begin{array}{l}\text { Fulfilled ICMJE criteria for } \\
\text { authorship. }\end{array}$ & Rention. \\
\hline
\end{tabular}

